\title{
Assessment of meat demand: A case study in the University of Ibadan for beef
}

\section{enterprise}

Babayemi, O. J., Ajayi, M. O., Akinsola, S. O. and Dauda, M. O.

Department of Animal Science, University of Ibadan, Nigeria

Abstract Author and email for correspondence: ojyemi@yahoo.co.uk

Poor adherence to food safety and wholesome practices in meat processing and handling is a common phenomenon in some public abattoirs in Nigeria. The quality of beef consumed by the University community is an issue of concern. Information on the extent of beef patronage has not been documented. Thus, beef demand at the University of Ibadan abattoir was assessed. Ante-mortem and post-mortem inspections by the University Veterinarian were performed on slaughter days from January 2013 to April 2015. The data collected were customer: day of purchase, Department/Unit, sex and rank. The quantity demanded and the parts requested were also noted. Data were analyzed using descriptive statistics. The results showed that a total of 22,884 contacts were recorded. An increase in patronage from $42.24 \%$ in 2013 to $57.76 \%$ in 2014 was evident. Women (53.60\%) requested for meat than male counterpart. The requests for $1-2 \mathrm{~kg}, 2-4 \mathrm{~kg}$ and above $4 \mathrm{~kg}$ at a time were $58.9 \%, 19.1 \%$ and $10.0 \%$ respectively. For the day of purchase, the patronage was higher on Fridays $(59.20 \%)$ as compared to Wednesdays. The last week of the month attracted higher demand $(36.20 \%)$ than weeks 1 (21.0\%), $2(22.3 \%)$ and 3 (20.5\%). A noticeable increase in demand was during festive periods. A high percentage occurred in the number of customers that specified the actual parts (63.5\%) of the meat requested and those that did not while females specified more $(57.82 \%)$ than males. Highest preference for special parts was observed among the Professors (45\%). More patronage was observed for people at closer Departments/Unit to the abattoir. It may be concluded that day of slaughter, proximity to slaughter house, sex, status and special occasions are vital factors that affect beef demand enterprise in the University of Ibadan.

Keywords: Beef demand; slaughter house; University of Ibadan

\section{Introduction}

Poor adherence to healthy practices in meat processing and handling is a common occurrence in most public abattoirs and meat shops in the developing countries. The reason might not be unconnected with the fact that public cattle slaughtering and processing are largely in the hands of none professionals who lack the technicality of livestock handling before and after processing dabble into the meat business as a means of livelihood without formal training. The operations are similar at the central abattoirs as well as in other satellite locations in case of big cities. Abattoir is any premises that is approved and registered by the controlling authority in which animals are slaughtered and dressed for human consumption (Codex Alimentarius, 1993). At the same time, it enables proper meat inspection to be carried out.

The process involved in cattle slaughtering are not religiously followed, whereby animals are not properly bled through a standard technique of hoisting and thus swiftly predispose the meat to microbial proliferation and gradual spoilage.

In Nigeria, since people are accustomed to eating beef together with the skin; the product obtained by the process of singeing (burning), and using all manner of devises 


\section{Assessment of meat demand}

such as kerosene (Babayemi and Bamikole, 2010). In certain times, some butchers consistently and ignorantly adopted the use of vehicle tyre to burn the cattle carcasses until the Federal Government put a halt in it. It is worst still when the butchers are seeing washing and cleaning the singed carcass on the very spot the cattle is slaughtered and burnt.

The quality of the cattle for slaughtering is another concerned aspect of meat consumption. It becomes horrendous when the butchers appear in their dirty wears; cutting carcass on a bare floor and leaving the meat open for hours until sold. In abattoir operation, a particular prerequisite programme has to be considered in order to offer rudimentary eco-friendly and operating conditions that are necessary for assembly of safe food from animal agriculture. These essential requirement platforms embrace decent business practices, worthy hygiene run-through and standard operating measures. According to Declan et al. (2004) these requirements are non-negotiable if the meat industry must serve the purpose but concluded that most abattoirs do not put these prerequisites into consideration during operation.

The type and the nature of the cattle to obtain for slaughtering and processingby the individual butchers is often determined by the financial capability of the operator. For example, cows that have over lived their usefulness afterseveralreproduction cycles are cheaper than any bull. Apart from the fact that beef from the old cattle is usually tough; the quality is lower, untendered with unacceptable organoleptic properties. Despite the fact that beef demand has been on the increase, meat consumption is greatly affected by consumers preference, as well as the standard of living, religion, belief, culture, income, food habit, colour, flavour, age, sex, socio-economic factor, individual variations and the poor state of most abattoirs (Desmond, 1990).

In the recent times, there is paradigm shift by the enlightened people from consuming questionable source of beef processing. The quality of beef consumed by the University community is an issue of concern. These elites at the apex of academic tower are familiar with practices indispensable for efficient slaughter hygiene and are therefore, selectively conscious of where they obtain their beef for household protein consumption. In order to meet this quest, an abattoir was rehabilitated in 2012 with a mandate to produce high quality beef for the University staff, students and the environs with over 300,000 people. Information on the extent of beef patronage has not been documented. Thus, beef demand at the University of Ibadan abattoir was assessed.

\section{Materials and methods}

The abattoir is located at the Teaching and Research Farm, University of Ibadan, Nigeria. The cattle to be slaughtered were obtained from the flock raised by fattening. On the eve of slaughter, the cattle were moved into the lairage and supplied with adequate clean water, inspected for judging and ante-mortem. The certified cattleby the University Veterinarian were restrained, bled, hoisted on rail, scalded, decapitated, eviscerated, post-mortem inspected, quartered and deboned. The operation was carried out on a washed-sterilized tiled floor. The harvested meat after deboningwas separated into primal cut and chunks.The organs were separated into liver, lungs, heart, kidney and spleen while rumen, reticulum, omasum and abomasum were disemboweled, cleaned, washed and salted to prevent spoilage. The large intestine and small intestine were also 


\section{Babayemi, Ajayi, Akinsola. and Dauda.}

cleaned severally with salt water to reduce the microbial spoilage. The rumen content and digesta were dumped and heaped away from the slaughter house.

Text messages were previously sent to all staff and other acquaintances outside the University in order to ask them to request for their meat needs ahead of the slaughter day. In sending the requests, they indicated the i r names, status, sex, Departments/Units, quantity desired and date. The response was downloaded while the requested meat was served, labeled accordingly and kept until the owner appeared. A table top-scale was used to measure the beef request in $\mathrm{kg}$ and checked twice at different points in order to ensure consistency and accuracy. The price tag was made on each beef parts, depending on the value. The datacollected were ratio of male to female patronage, quantity of purchase on the scale of $1.0-2.0 \mathrm{~kg}, 2.1-$ $4.0 \mathrm{~kg}$, and above $4.0 \mathrm{~kg}$. Data obtained were analyzed using descriptive statistics.

\section{Results and discussion}

Presented in Figure 1 is the record of the people that patronized the purchase of beef between January 2013 and April 2015. The results showed that a total of 22,884 contacts were made within the 28 months. A progressive increase of demand was noticed showing the percentages of 35.36, 48.35 and 16.29 for 2013, 2014 and 2015 of January-April, respectively. The seeming decrease for 2015 was so as the report for the present study was terminated in the first quarter of that year. The noticeable increase in patronage in year 2014 and to the early period of 2015 may be due to the fact that the university staff was informed about the re-opening of the slaughter house and of the wholesome techniques of processing. The hygienic environment and healthy animals slaughtered coupled with its consistency of operation could also contributed to the increasing number of patronage. However, the upsurge in demand could be as a result of the universal awareness of the tremendous nutritional significance of eating meat. Notwithstanding, the high demand may be linked to the natural increase in the human population in the recent times. Regmi (2007) noted the unprecedented population growth that has occurred in the last half of the century created an additional demand for meat and general food in developing countries.
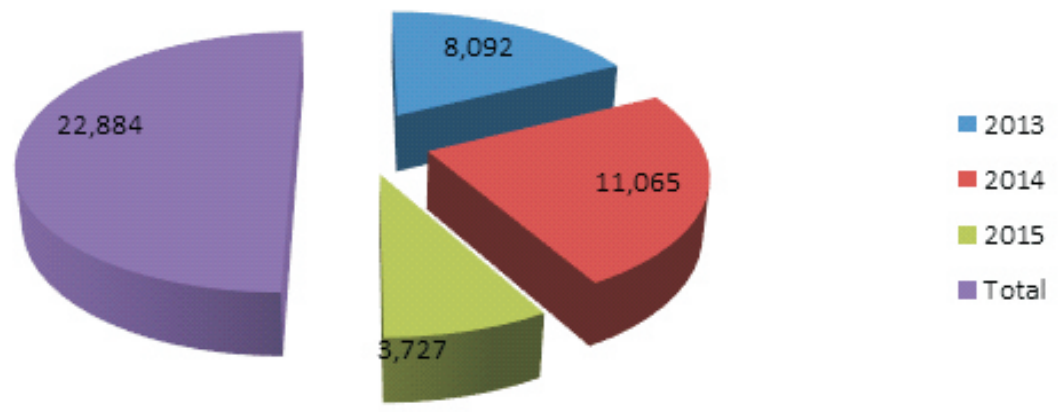

Figure 1: Beef patronage in 2013, 2014 and 2015 at University of Ibadan slaughter house 
The high patronage was expected to happen in a place like this, being a University, where standard ways of doing things are domicile. Although the slaughter house of the University of Ibadan might not yet have met the international standard, the rule of hygiene was strictly adhered to such that the requisite facilities were not compromised with, which included borehole, effective cold-room and numerous freezers. Such high level of hygiene may be an overriding factor that attracted the unprecedented increase of beef demand.
Figure 2 shows the comparative day of purchase of beef which were Wednesday and Friday of the week. It revealed that $40.80 \%$ and $59.20 \%$ contacts were made for Wednesday and Friday, respectively. Low percentage of beef consumption for Wednesday may not indicate low consumption but beingamid-week day. Friday is always the beginning of week end during which all members of the family often aggregate and sometimes entertains visitors, given rise to an enhanced purchase. Presented in Figure 3 is the frequency at which male and female endeavoured to purchase beef in the slaughter house. The trend was such that the female had $7.10 \%$ higher purchase of beef than male.

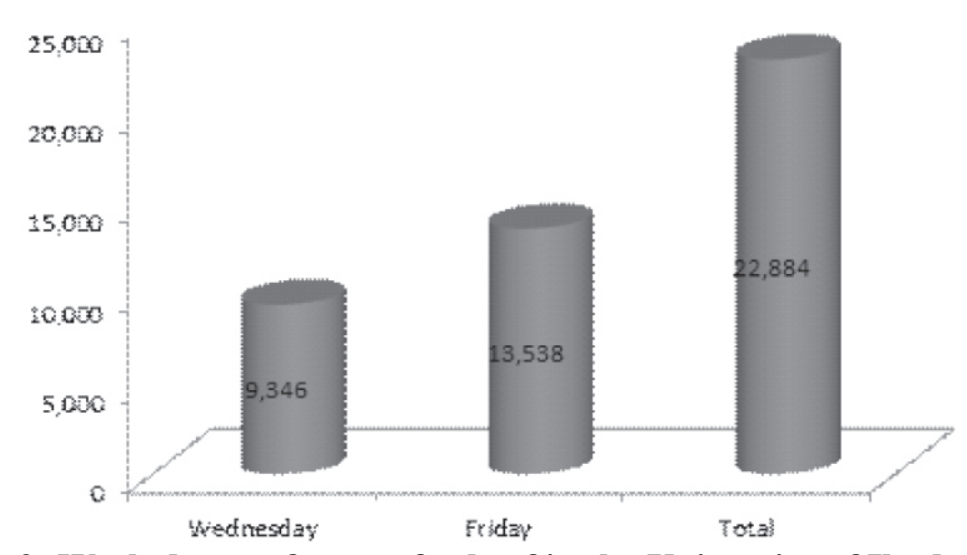

Figure 2: Week day preference for beef in the University of Ibadan abattoir

Although male staff population is more than that of female counterpart, higher demand for beef by the latter was normal. The reason for more female patronage could be due to their natural ability to source for the desired food for the household. Cultural tradition, which makes it the duty of the wife to go to the markets, buy meat and prepare delicacy for the family while the husband essentially empower the wife with money could also be a factor. Praettaelae et al. (2006) reported that women are more concerned about a healthy diet and about food choices in general. In Nigeria, women are predominantly house keepers and derive satisfaction in getting cheap and quality foodstuff for the family. 


\section{Babayemi, Ajayi, Akinsola. and Dauda.}

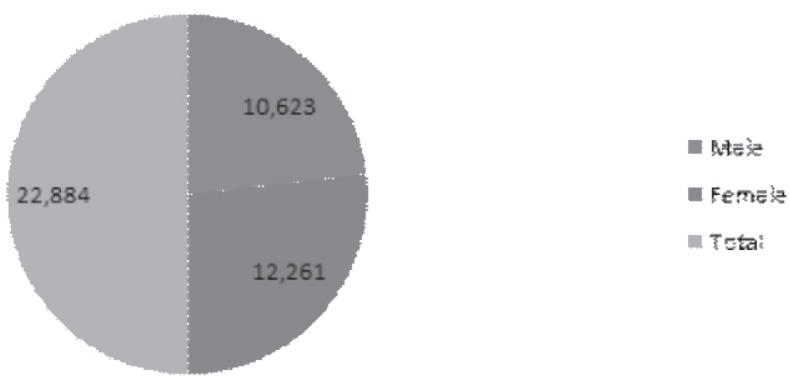

Figure 3: Male and female response to beef purchase in the University between 2013 and 2015

The monthly patronage of beef is presented in Table 1. It ranged from 4,687 in week three to 8,292 in week four. The higher percentage $(36.20 \%)$ for beef demand in the fourth week of the month may be due to the increased cash flow whenever the income improves. Since salaries are often paid at the end of the month, the enhanced demand for food items including animal agriculture was expected. This may actually be explained with the downward decrease of the beef purchase in the subsequent weeks of the month when almost the salary was used according to the budget.

Table 1: Monthly patronage of beef at the University of Ibadan abattoir between January 2013 and April 2015

\begin{tabular}{lll}
\hline Week & & Percent \\
\hline First week & 4,807 & 21.00 \\
Second week & 5,098 & 22.30 \\
Third week & 4,687 & 20.50 \\
Fourth week & 8,292 & 36.20 \\
Total & 22,884 & 100.00 \\
\hline
\end{tabular}

The patronage of beef by people from the different faculties across the University of Ibadan is presented in Figure 4. The number of contact ranged from the least (93) in Public Health to the highest $(4,205)$ in Agriculture and Forestry. The particular reason for the wide difference among the faculties was not known. Reason of proximity might be attributed to the low patronage by some faculties, especially those at theCollege of Medicine, Public Health and Clinical Sciences that are very far away. On the other hand, when some of these far away faculties are compared with some of the close ones, the difference was marginal. Critical look at the population as a factor might be far from the reason for the high patronage of beef by some faculties (Agriculture and Forestry, Arts, Sciences,
Technology, Veterinary Medicine, Education and Central Administration). The holistic expression of the faculties may be inferred that the extent of patronage was more of attitude, notion about red meat and general awareness.

Despite the fact that text messages are sent out every week to every staff of the University community, asking them to book ahead the stipulated dates in the week, the majority would still forget. However, many people sometimes claimed they never received such prior information to request. The allusion could true as there might be probability that they were inadvertently omitted from the list of staff or due to any other error arose in the baseline collation. Notwithstanding, a particular reference may be made to the high beef patronizing 


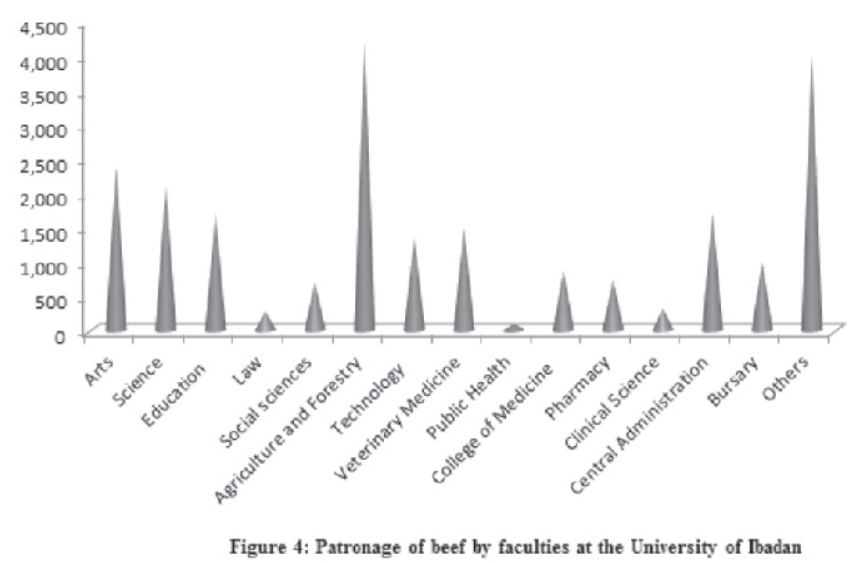

faculties including Agriculture and Forestry $>$ Arts $>$ Science $>$ Education $>$ Central Administration $>$ Veterinary Medicine $>$ Technology. It should be noted that a group of people (Others) as shown in the Figure 4, could not be classified into the faculty, probably they did not indicate it at the point of requesting for the beef or were not members of the University community. Shown in Table 2 is the effect of status on beef demand and preference for special parts at the University of Ibadan abattoir. The number of staff that did not specify the parts of beef ranged from 1,000 by the Professors to 10,484 by others. This is expected as the number of Professors $<$ Doctors $<$ Others. It may be interesting to note that composition of status as 'Doctors' and 'others' were teaching and none teaching staff.

Table 2: Effect of status on beef demand and preference for special parts at the University of Ibadan abattoir

\begin{tabular}{llll}
\hline Status & $\begin{array}{l}\text { No specification for } \\
\text { special part }\end{array}$ & $\begin{array}{l}\text { Specification for } \\
\text { special parts }\end{array}$ & Total \\
\hline Professors & 1,000 & 453 & 1,453 \\
Doctors & 5,340 & 1,879 & 7,219 \\
Others & 10,484 & 3,728 & 14,212 \\
Total & 16,824 & 6,060 & 22,884 \\
\hline
\end{tabular}

The reason for the low patronage by the high class in the University community may be due to their relative low population and the average older age by trying to be mindful of the type of meat, frequency of eating and the quantity. According to Senhui et al. (2003) when people are becoming old they are more conscious of their health and nutrition and as such reduce the intake of some meat and its products, especially red meat.However, the ratio of those that did not specify the part of the meat in their request to those that did was $7: 3$ for all the category of the staff.

The classification of the quantity of beef demanded from the abattoir of the University of Ibadan is presented in Figure 5. The range of the quantity of beef demanded on request were $1-2 \mathrm{~kg}, 2.1-4 \mathrm{~kg}$, $4.1-6 \mathrm{~kg}$ and $6.1 \mathrm{~kg}$ and above. The highest number otherwise known as majority asked for a service of maximum of $2 \mathrm{~kg}$ of beef. It was observed that fewer people asked for high quantity of beef. However, the other extreme in asking for larger quantity of beef especially those between $6.1-10 \mathrm{~kg}$ was also 


\section{Babayemi, Ajayi, Akinsola. and Dauda.}

noted. This category of buyers might not necessarily be using it only for domestic purposes but might obtained it to entertain visitors, be shared among friends and neighbours and undoubtedly for ceremonies. The varying responseto be purchasedmay be due to the level of income, price, family size and level of education.

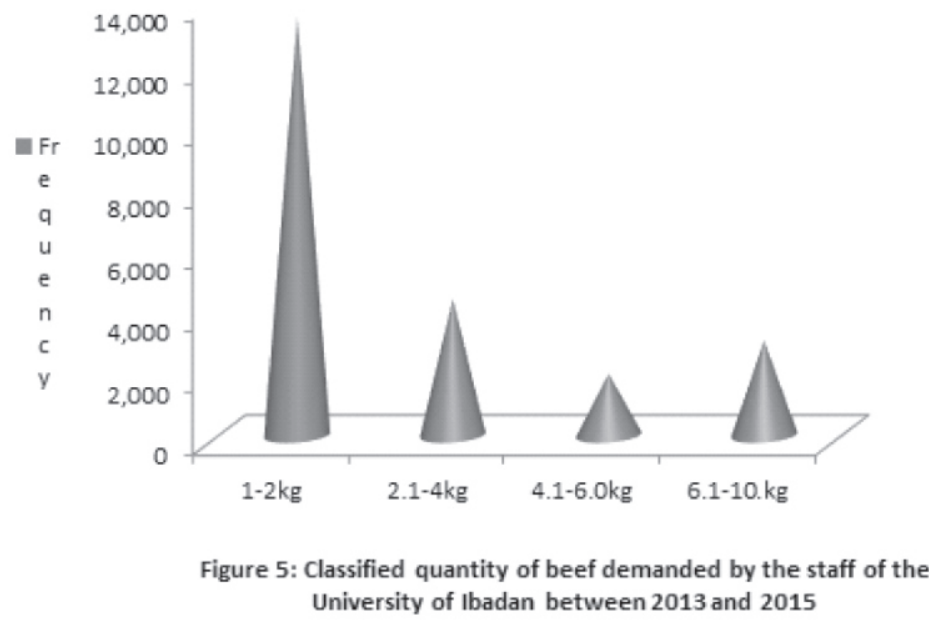

Robert and Nwaiwu (2012) analyzed the consumption pattern of beef and fish in Nigeria, and established that beef consumption increase with age, level of education, price of substitutes and household size. This finding further supports the report of Damisa and Hassan (2009) that factors such as income, price, household size and level of education influence the consumption of meat. Burton and Young (1992) and Koppert and Hladik (1990) agreed that factors that affect the consumption of meat can be classified as economic, social and cultural factors, while Ojewola and Onwuka (2001) specifically highlighted religion, age, sex, socioeconomic factors, individual variation and income as major factors in the Nigeria environment.

\section{Conclusion}

The study showed thatdayand week of slaughtering, nature of faculty discipline, proximity to abattoir, sex, and status of the customers, standard hygiene practices, consistent operations and prompt servicesweresome of the vital factors that positively affectedthe high beef patronage at the University of Ibadan abattoir.

\section{Acknowledgement}

The first author acknowledged the abattoir management authority of the University of Ibadan for having access to the data and financing the publication.

\section{References}

Agaie, B. M., Magaji, A. A. and Sofanda, M. L. 1997. Slaughter of food animal in Sokoto metropolis and meat availability in Sokoto. Nigeria Journal of Basic and Applied Science. 6(1): 65-70.

Burton, M. P. and Young, T. 1992. The structure of changing tastes for meat and fish in Great Britain. 


\section{Assessment of meat demand}

European Review of Agricultural Economics.

Codex Alimentarius 1993. Code of Hygiene practice for meat (CAC/RCP 58- 200005 ) http://www.codex alimentarius .net/download/standard/10196/cx p_0 58e Retrieved 2010-0211.

Damisa, M. A. and Hassan, M. B. 2009. Analysis of Factors Influencing the Consumption of poultry meat in the Zaria Emirate of Kaduna State, Nigeria. European Journal of Educational Studies 1(1): Pp. 15.

Declan, J. B., Alice, M. D. and James, J. S. 2004 . B e ef H ACP: Intervention a $\mathrm{n} \mathrm{d} \quad \mathrm{n}$ o $\mathrm{n}$ i n t e r ve n t i o n s y s t e m. International Journal of Food Microbiology.66 (1-2): 119-129.

Desmond, A. 1990. Cattle and buffalo meat production in the tropic. Longman Printing Press, Ibadan

FAO (Food and Agricultural Organization of the United Nations) 2009. The State of Food and Agriculture. Livestock in the Balance. Rome.

Jimenez-Colmenero, F., Carballo, J. and Cofrades, S. 2001. Healthier meat and meat products: Their role as functional foods. Meat Science Journal 59: 5-13.

Koppert, G. and Hladik, G. C. M., 1990. Measuring Food consumption. In (Food and Nutrition in African $\mathrm{R}$ a $\mathrm{i} n$ Forest Ed. by Hladik, C. M., Bahuchet, S. and Degarine, I. UNESCO/NAB Paris).
Ojewola, G. S. and Onwuka, G. I. 2001. Evaluation of the organoleptic properties of "Suya" produced from various sources of meat. Nigerian Journal of Animal Production.28(2), 199-201.

Praettaelae, R., Paalanen, L., Grinberga, D., Helasoja, V., Kasmel, A. and Petkeviciene, J. 2006. Gender differences in the consumption of meat, fruit and vegetables are similar in Finland and the Baltic countries. European Journal of Public Health.17(5): 520-525.

Regmi, A. 2007. Urbanization and Food Consumption. A USDA City Study. Retrieved on January $27^{\text {th }} 2007$ from ers-usda.gov/--/fau-us-a g ri c u l t u ral - t r a d e update/fau125. aspx.

Robert, U. and Nwaiwu, J. 2012. Microlevel analysis of beef and fish consumption in Imo state, Nigeria. Agricultural Research and review 1(1), 1-8.

SenhuiHe, S. F. and Arbindra, R. 2003. Identifying factors influencing beef, poultry and sea foods consumption. Journal of food distribution research, 34 ( 1 ): Page50-55.

Received: $7^{\text {th }}$ February, 2017 Accepted: $21^{\text {st } J u n e, ~} 2017$ 